\section{Is EGFR expression important in non- small cell lung cancer?}

\section{S M Lee}

\section{There are still many unanswered questions on the use of EGFR treatment in NSCLC}

$\mathrm{E}$ pidermal growth factor receptor (EGFR), a receptor tyrosine kinase, is frequently overexpressed in nonsmall cell lung cancer (NSCLC). These receptors play an important role in tumour cell survival and activated phosphorylated EGFR results in the phosphorylation of downstream proteins that cause cell proliferation, invasion, metastasis, and inhibition of apoptosis. Expression appears to be dependent on histological subtypes, most frequently expressed in squamous cell carcinoma but also frequently expressed in adenocarcinomas and large cell carcinomas. Not surprisingly, there are many published reports attempting to correlate the relationship between EGFR protein overexpression and survival. However, the data regarding the prognostic role of EGFR expression are inconsistent and confusing, with some reports indicating that EGFR is associated with poor survival while no prognostic association was seen in other reports.

In this issue of Thorax Nakamura et al carried out a meta-analysis of 18 studies (including nearly 3000 patients), reviewing whether EGFR overexpression has an impact on survival. Most of these reported studies evaluated EGFR protein expression by immunohistochemistry (IHC) and it is possible that different conclusions may reflect differences in incubation and detection methods, reagents, assay cut off points, and population studied with different stages. Nevertheless, EGFR overexpression was seen in 39\% in adenocarcinoma, $58 \%$ in squamous cell carcinoma, and $38 \%$ in large cell carcinoma, and they concluded that EGFR protein overexpression using the IHC method was not associated with a poorer prognosis. However, we have less information about whether expression based on EGFR gene copy number or EGFR gene mutations impacts on survival. A recent report $^{3}$ suggests that EGFR mutations are not associated with poorer survival. However, investigators at the University of Colorado showed that the EGFR gene copy number quantified by fluorescence in situ hybridisation (FISH) may be correlated with a poorer prognosis.

A much more important issue for patients with NSCLC is whether a relationship exists between EGFR expression and survival benefit with EGFR inhibitor therapy. This might disadvantage patients with negative or low EGFR expression who might benefit from EGFR inhibitor treatment as most trials involving EGFR blockade preclude patients with no EGFR protein expression. Two EGFR inhibitors, gefitinib (Iressa) and erlotinib (Tarceva), have been approved in the United States for use as second line or third line treatment in advanced NSCLC. In the landmark BR21 randomised, placebo controlled, phase III study from NCI Canada, treatment with erlotinib improved median overall survival from 4.7 months to 6.7 months and 1 year survival rates from $22 \%$ to $31 \%$ in patients with advanced NSCLC who had progressive metastatic disease after receiving chemotherapy, but the status of EGFR protein expression was not predictive for survival benefit to erlotinib. ${ }^{4}$ In retrospective studies related to gefitinib from the IDEAL trials, no association was observed between EGFR protein expression, response, and survival benefit. ${ }^{56}$ In both the BR21 and IDEAL trials, higher response rates were seen in patients who were never smokers, female, Asians, and with adenocarcinomatous histology. This is in contrast to a study from Colorado which showed a significant correlation between levels of EGFR expression (using a different antibody) and sensitivity to gefitinib. ${ }^{7}$ The group also showed that quantifying EGFR gene copy number with FISH technology offers a better prediction of sensitivity and survival to EGFR inhibitors, but this needs to be proved in prospective large scale randomised studies. The US Food and Drug Administration (FDA) recently revised the approval of gefitinib labelling to be used only in patients who had already taken the medicine because, in a large recently reported randomised trial (ISEL, Iressa Survival
Evaluation in Lung Cancer) involving nearly 1700 patients, gefitinib did not improve survival in the general study population. However, subgroup analyses showed that gefitinib significantly improved survival in patients of Asian ethnicity and in those who had never smoked. ${ }^{12}$

In the past 12 months three groups have reported an important association between somatic mutations in the EGFR gene at the tyrosine kinase domain and a dramatic response to gefitinib and erlotinib. $^{8-10}$ The EGFR domain mutations frequently involved either inframe deletions in exon 19, single missense mutations in exon 21 , or inframe duplications/insertions in exon 20 and were not associated with clinical stage or survival. ${ }^{3}$ Interestingly, these mutations were statistically more frequent in never smokers than in smokers (51\% $v 14 \%)$, in adenocarcinomas than in other histological types ( $40 \% v 3 \%$ ), in patients of East Asian ethnicity $(30 \% v$ $8 \%)$, and in women than in men $(42 \% v$ $14 \%) .{ }^{3}$ These findings are very similar to the clinical characteristics of patients responding to gefitinib or erlotinib treatment in the IDEAL and BR21 studies, respectively. ${ }^{4-6}$ Despite the dramatic responses to such inhibitors, most patients ultimately relapse. Similar to the paradigm with imatinib treatment in gastrointestinal stromal tumours and chronic myeloid leukaemia, this was recently shown to be due to acquisition of a second mutation (at position T790M) in the catalytic cleft of the EGFR tyrosine kinase domain, thereby preventing access by gefitinib. ${ }^{11}$

There are still many important unanswered questions concerning EGFR treatment. While the association between these mutations and the dramatic response to gefitinib or erlotinib has been shown, we are still unclear why survival benefit is seen in the majority of the BR2l patients with stable disease with symptomatic response who appear to have no EGFR mutations when treated with erlotinib. Indeed, in the BR2l study, survival after treatment with erlotinib was not influenced by EGFR gene mutations. ${ }^{4}$ Moreover, in a study reported by the Colorado group, $40 \%$ of their patients with EGFR mutations developed progressive disease and $32 \%$ of their nonmutated EGFR group had disease control following gefitinib treatment. ${ }^{7}$ We still do not know whether all the described mutations are of equal clinical relevance. Based on the current clinical data available, we must therefore acknowledge that EGFR mutations or expression status per se do not quantify use as predictive markers for selection of NSCLC patients to treatment with EGFR 
inhibitors. A meta-analysis of the data obtained from the BRI2 and ISEL studies may indicate whether EGFR expression confers a survival advantage in patients treated with EGFR inhibitors. The findings described above refer to relapsed NSCLC patients. However, we do not have any data on the role of EGFR monotherapy when used as first line treatment, particularly in poor performance patients or as maintenance treatment following chemotherapy. Prospective large scale clinical studies with translational component need to be performed to identify the most optimal paradigm for selection of patients for treatment with EGFR inhibitors. Defining the mechanisms of resistance to EGFR inhibitors, coupled with identifying the molecular and clinical profile of responding versus non-responding patients in ongoing trials, remains a very important priority. A randomised phase III study examining the role of EGFR inhibition as first line treatment for patients with advanced NSCLC is currently in progress in the UK, attempting to answer some of these questions.

Thorax 2006;61:98-99.

doi: 10.1136/thx.2005.047936

Correspondence to: $\operatorname{Dr} S \mathrm{M}$ Lee, Meyerstein Institute of Oncology, Middlesex/UCLH

Hospitals, Mortimer Street, London WIT 3AA,

UK; smlee@ucl.ac.uk

Competing interests: none declared

\section{REFERENCES}

1 Hirsch FR Varella-Garcia M, Bunn PA Jr, et al. Epidermal growth factor receptor in non-small-cell lung carcinomas: correlation between gene copy number and protein expression and impact on prognosis. J Clin Oncol 2003;21:3798-807.

2 Nakamura $\mathrm{H}$, Kawasaki N, Taguchi $\mathrm{M}$, et al. Survival impact of epidermal growth factor receptor overexpression in patients with nonsmall-cell lung cancer: a meta-analysis. Thorax 2006:61:140-5

3 Shigematsu H, Lin L, Takahashi T, et al. Clinical and biological features associated with epidermal growth factor receptor gene mutations in lung cancers. J Natl Cancer Inst 2005;97:339-46.

4 Shepherd FA, Pereira J, Ciuleanu TE, et al. Erlotinib in previously treated non-small-cell lung cancer. N Engl J Med 2005;353:123-32.

5 Fukuoka M, Yano S, Giaccone G, et al. Multiinstitutional randomised phase II trial of gefitinib for previously treated patients with advanced non-small cell lung cancer (the IDEAL 1 Trial) $J$ Clin Oncol 2003;21:2237-46.

6 Kris MG, Natale RB, Herbst RS, et al. Efficacy of gefitinib, an inhibitor of the epidermal growth factor receptor tyrosine kinase, in symptomatic patients with non-small cell lung cancer: a randomised trial. JAMA 2003;290:2149-58.

7 Capuzzo F, Hirsch FR, Rossi E, et al. Epidermal growth factor receptor gene and protein and gefitinib sensitivity in non-small-cell lung cancer. J Natl Cancer Inst 2005;97:643-55.

8 Lynch TJ, Bell DW, Sordella R, et al. Activating mutations in the epidermal growth factor receptor underlying responsiveness of non-small-cell lung cancer to gefitinib. $N$ Engl J Med 2004;350:2129-39.

9 Paez JG, Janne PA, Lee JC, et al. EGFR mutations in lung cancer: correlation with clinical response to gefitinib therapy. Science 2004;304:1497-500.

10 Pao W, Miller V, Zakowski M, et al. EGF receptor gene mutations are common in lung cancers from 'never smokers' and are associated with sensitivity of tumors to gefitinib and erlotinib. Proc Natl Acad Sci USA 2004;101:13306-11.

11 Kobayashi S, Boggon TJ, Dayaram T, et al. EGFR mutation and resistance of non-small-cell lung cancer to gefitinib. N Engl J Med 2005;352:786-92

12 Thatcher N, Chang A, Parikh P, et al. ISEL: a phase III survival study comparing gefitinib (Iressa) plus best supportive care (BSC) with placebo plus BSC, in patients with advanced nonsmall-cell lung cancer (NSCLC) who had received one or two prior chemotherapy regimens. Lung Cancer 2005;49(Suppl 2):S4.

\section{Committee on Publication Ethics - Seminar 2006}

\subsection{0am-5pm Friday 10th March 2006, BMA House, London, UK}

This year's seminar takes an international perspective and addresses publication ethics and research in several European countries and beyond, with interactive workshops on common ethical and editorial dilemmas. The manipulation of impact factors, and whether unethical, will also be considered.

The seminar is for editors, authors, and all those interested in increasing the standard of publication ethics. The seminar will include:

- Professor Michael Farthing - the Panel for Research Integrity (UK)

- Publication ethics and research in other countries, including those in Northern Europe, Turkey, and China

- Publication ethics in animal research

- Making the COPE website work for you - real time demonstration on how to use the website

- New indexing services

- Interactive workshops - common ethical and editorial dilemmas for editors

- Opportunities to network with other editors and share your experiences and challenges

The seminar is free for COPE members and $£ 30.00+$ VAT for non-members. Numbers are limited and early booking is advisable. For registrations or more information please contact the COPE Secretary at cope@bmigroup.com or call 020-7383-6602

For more information on COPE see www.publicationethics.org.uk 